\title{
Market Volatility and Momentum: Evidence from Pakistani Stock Exchange
}

\author{
Anila Rafique Khan ${ }^{1 *}$, Muhammad Waqas ${ }^{1}$, Arshad Hassan ${ }^{1}$
}

\begin{abstract}
This study explores the relationship between market volatility and momentum profitability. This study indicates that market state volatility has significant power to forecast momentum payoffs, especially in negative market states. The results are the context in the presence of market state and business cycle variables. Market premium is significant and negative. Market volatility is also found negatively influencing momentum profits. Volatility is divided into volatility in the positive market and volatility in the negative market. Both are significantly and negatively influencing momentum profits. Vol+ and Vol- both have negative signs; Vol- is dominant in terms of the magnitudes of the coefficient and the t-statistics. Business cycle effect measured by term and yield is not found significant. Non-linearity has not been observed regarding the term. Results are found robust for market adjusted momentum payoff. The study also explores the impact of market state, volatility and business cycles on the return of loser and winner portfolio. This study reports that returns of the loser portfolios are explained by market component, whereas volatility is found to be insignificant. The macroeconomic variables TERM, TERM2 and YLD show signs of statistical significance. Market factor is significantly and positively influencing winner portfolios. The results indicate that volatile markets forecast low returns on winner stocks. Return dispersion used to measures cross-sectional is also found significant. The study recommends that investors should devise investment and momentum strategies on the basis of the volatility of stocks and the business cycle. The tests of this study show that volatile down markets forecast low momentum payoffs. The timeseries predictability of momentum is asymmetric, which arises from loser stocks.
\end{abstract}

Keywords: Market volatility, Momentum, Time-series predictability of momentum.

\section{Introduction}

Market volatility is the up and down movement measured by standard deviation from the expectation. When the stock market rises one day and down for the next three and then up again so this up and down movement is called stock market volatility. Volatility is frequently referred to as a risk indicator as high price fluctuations can

https://doi.org/10.30537/sijmb.v4i1.105

${ }^{1}$ Capital University of Science and Technology, Islamabad, Pakistan

* Corresponding Author: anilarafiquekhan@ hotmail.com 
signal uncertainty in the markets and the powers among buyers and sellers are regularly shifting.

Momentum is frequently referred to as trend power. Momentum strategy believes that stock which has performed well will be doing so also in the future. So it focuses on buying stocks with good historical performance and selling stock which has done worse. Market momentum is the expected market changes which are likely to occur in the near future. It is the change in price as well as volume.

Market momentum is the expected strength of the positive or negative change in the market price. How prices change during a specific period of time versus volume during that period remains a matter of debate. Traders who do not know how to exercise volatility and momentum information in their trading frequently find themselves in trades where risk cannot be controlled or enter the markets on the incorrect nodes. Momentums strategies can help out investors beat the market and keep away from losses.

Wang and $\mathrm{Xu}$ (2015), examine the momentum predictability. The study captures idea from the extreme 2008-2009 instance, and explore whether market volatility is related to momentum. The study discovers that volatility of marketplace has significant and powerful predictive influence on momentum earnings, particularly in negative market states. Momentum profitability is high for a firm that has high information ambiguity or high default risk. The study demonstrates that unstable losing markets predict low momentum payoffs. The time-series predictability of momentum is not smooth for loser stocks.

Wang and $\mathrm{Xu}$ (2015), investigate market volatility as a forecaster of momentum profits. The analyses show that the prognostic benefit of the volatility of the market for momentums proceeds is strong and significant. The study consists of two most important results. The first one is that the stock market volatility gives a strong empirical description of the time series predictability of momentum. The study finds out that high market volatility predicts low down momentum benefit, so this relation is more robust in downwards marketplaces. The negatively linked, market volatility and market condition harmonize all other in the foretelling of momentum payoffs. Momentum earnings are different clearly among positive market states of low down volatility and unstable downwards markets. Secondly, the time-variation in momentum profits has a remarkable characteristic. The study observes asymmetric predictability between loser and winner portfolio.

The study of Wang and Xu (2015), have broadened the results of Cooper, Gutierrez, and Hameed (2004) in two significant ways. First, Wang and Xu (2015), explore volatility as a predictor of momentum payoffs. Market volatility put in significant predictive influence in down marketplaces. Jointly, volatility of market and markets state control many other variables and with the most vigorous depiction of the time-

Sukkur IBA Journal of Management and Business | Volume 4 No. 1 January - June 2017 @ Sukkur IBA University 
varying momentum earnings. Secondly, the study report loser-centered predictability. The loser stocks generally have comparatively high earnings following volatile down market. These recent results present a fascinating defy to a number of theories, both conduct, and risk-based, which may have recently been anticipated to describe the momentum effect. Daniel, Hirshleifer, and Subrahmanyam (1998), for instance, imagine many investors are too confident of their confidential selective information and react excessively to it.

Wang and $\mathrm{Xu}$ (2015), investigate the predictive benefits on the volatility of market intended for the profitability of momentum. Wang and $\mathrm{Xu}$ (2015), reveal that the volatility has a strong influence towards predict momentum payoff. Distinct business cycle along with variables of market state, report the significant influence of the market volatility on momentum sorted portfolio. Further, the forecasting role of the volatility of market continues along with market state and variables of the business cycle. Just market state persists in reporting forecasting force for momentum effectiveness.

\section{Literature Review}

Just similar to various models, this behavioral model creates indirect suggestions that are symmetric among positive and negative information. Facts that market state and market volatility predict momentum income are supporting to the model if the performance of the winners and losers portfolio are symmetrically knowable. A further example is a behavioral theory developed by (Hong, Lim, \& Stein, 2000; Hong \& Stein, 1999). That provides that personal information spreads slowly but surely in the marketplace, which causes under-reaction. Hong et al. (2000), present verification that information spreading is slow pro unfortunate thing. Though Wang and $\mathrm{Xu}$ (2015), result that high volatility in downwards markets forecasts high earnings on lower stocks is consistent among investor overreaction, not under-reaction, towards negative information in the terrible period.

The result of momentum, formerly discovered by Jegadeesh and Titman (1993), has been widely examined. Results of, Cooper et al. (2004) and Avramov, Chordia, Jostova, and Philipov (2007) are strongly related to Wang and Xu (2015). Cooper et al. (2004), focus on time-series predictability. The study concludes that momentum profits rely upon market circumstances. It is deduced as helpful proof for overreaction models. Avramov et al. (2007), reveal a cross-sectional association among momentum and credit rating and discover that momentum earnings are extremely significant for low-quality firms, but an absent in high-grade firms. Wang and $\mathrm{Xu}$ (2015), provide that volatility of market has prognostic force intended for variation of time into momentum payoffs.

Chordia and Shivakumar (2002), concentrate on the function of the business cycle in elucidation momentums. Wang and $\mathrm{Xu}$ (2015), focus on the direction of the volatility of market used for the profitability of momentum. Their findings are not in line with

Sukkur IBA Journal of Management and Business | Volume 4 No. 1 January - June 2017 @ Sukkur IBA University 
the studies of Chordia and Shivakumar (2002) and Cooper et al. (2004) that are supported by the business cycles risk justification and the behavioral theory. Wang and $\mathrm{Xu}$ (2015), results are impressing when evaluated with several Cross-Sectional findings. The findings of Jiang, Lee, and Zhang (2005) and Zhang and Li (2006) illustrate that payoffs of momentum are superior amongst organizations with high data ambiguity. On the other hand, Wang and $\mathrm{Xu}$ (2015) locate that high periods of volatility are followed by small momentum payoff. Though momentums have crosssectional, but effect analysis demonstrates that time series aspect is essential in favor of designing a momentum convincing theory. Their results indicate contradiction to present work on momentum. The study also reports that volatilities to the link to returns forecasting. Past researchers have investigated the time series relationship among volatility of markets and the expected returns of the market. Their findings widen this distinctive line of research by evaluating the time-series association among market volatility and momentum profitability.

The cross-sectional testing of determinants of momentum profits by Avramov et al. (2007) appears to recommend that payoffs of momentums are high in down markets as default risk is a foremost concern. The time-series analysis of Cooper et al. (2004) conversely shows that payoffs of momentums are significant in positive market states. The dissimilarity among the Cross-Sectional as well as Time series results are puzzles that Avramov et al. (2007) highlight but Wang and Xu (2015) point to the subsequent justification of this puzzle. On the other hand, investors are anxious about default risk in downwards markets, mainly for loss stocks by low credit ratings. Investors sell the loser stocks to escape high default risk in unstable down marketplaces the following loser change providers grow to negative momentum payoffs. On the other side, investors are too confident in high-quality market settings with disregard to negative phases of loss stocks with mostly credit risk. Sometimes investors over-buy loser stocks in the excellent period, making significant momentum earnings. Constant to the opinion that losers stock are comparatively overbought in fine time, Wang and $\mathrm{Xu}$ (2015) discover that the lofty market states predicted small profits, comparative to the market return within the similar time, on loser stocks.

Latest studies have revealed the significance of momentums for assured subsets of stock and shares. Jiang et al. (2005) and Zhang and Li (2006), comprehend that payoff of momentum is high along with organizations by means of higher information ambiguity. The proxy server information vagueness by organization size, firm age, and specialist predict dispersion, volatility of cash flow, and volatility of stock returns. These cross-sectional conclusions seem to recommend that momentum payoffs are higher in the occurrence of high market ambiguity which is in contradiction to (Wang $\& \mathrm{Xu}, 2015)$. The difference between cross-sectional and time series result is alike towards the puzzle highlighted by (Avramov et al., 2007). The empirical proof is steady with the above loser-centered description. In down markets, the journey to security arises such that investors over-sell loser stocks with high information ambiguity, giving

Sukkur IBA Journal of Management and Business | Volume 4 No. 1 January - June 2017 @ Sukkur IBA University 
rise to low momentum payoffs. In superior market circumstances, investors are violent in looking for comparatively cheap stocks and shares such that they buy in excessive quantity insolvent stockpiles allied with higher information ambiguity, making high momentum payoffs. Wang and $\mathrm{Xu}(2015)$, results propose an easy approach to improve profits of momentum investing. In the case of the lagged 12 months, volatility is high than the annualized lagged 36 months volatility, they explain it as a month of high volatility.

Wang and $\mathrm{Xu}$ (2015), inspect the prognostic benefits of the volatility of the market in favor of momentums. They state with the purpose of (1) market volatility have important capability towards predicting momentum payoff, it is vigorous later than regulating on behalf of business cycle variables as well as market state; (2) the market volatility attracts largely of the prognostic influence of market state; (3) subsequent to managing meant for market state along with market volatility but other variables don't have progressive foretelling force; (4) time series forecasting profit of volatility of marketplace be devoted to failure stockpile; furthermore (5) the defaulting probability help to describe the forecasting strength of volatility of market pro momentum. All these results mutually show a substantial defy to present assumptions lying on momentum.

Several theoretical and empirical works on volatility on the basis of volatility weighting exist. (Hallerbach (2012), 2014)) use weighting strategy via their own volatility and for the same purpose of uses normalized returns. According to Barroso and Santa-Clara (2015), the process of weighting cross-sectional equity momentum through their volatility is extremely helpful to improve their risk-adjusted performance: the process of executing the volatility-weighting doubles the Sharpe ratio. The process of the categorization of stock according to their precedent residuary rather of overall return produces an additional constant edition of momentum (Blitz, Huij, \& Martens, 2011).

Lee and Swaminathan (2000), shows that momentum is stronger for stocks with high trading volume. To the extent that both volume and forecast dispersion that measure the difference of opinion, momentum profits are related to both variable under the hypothesis that differences in beliefs intensify return persistence. Hou and Moskowitz (2005), find that the price of stocks with higher residual volatility reveals delay in the incorporation of information. In several pricing models, the risk is measured by market volatility, and change in market volatility is found to influence the future income on all assets. The role of changes in volatility is helpful in explaining the change in expected profit over time (Harvey \& Whaley, 1992).

Makarov and Rytchkov (2012), demonstrate that heterogeneous information can lead to momentum. Conrad and Kaul (1998), examine prominent verification signifying that the profits of momentum are ascription to the cross-sectional difference in

Sukkur IBA Journal of Management and Business | Volume 4 No. 1 January - June 2017 @ Sukkur IBA University 
expected returns relatively than to any time series reliance in return. The innovative result acknowledged by Jegadeesh and Titman (1993) have consequently been extensive in various findings. Like, Rouwenhorst (1998) discover related momentum profit in the European markets, Moskowitz and Grinblatt (1999) discover profit of momentum a cross-industry sorted portfolio, and Grundy and Martin (2001) investigate the strategy of momentum have been persistently painful in the United State ever since 1920.

Jegadeesh and Titman (1993), direct to the scope that higher past return might be partially due to higher expected return, the winners' portfolio could possibly include higher risk stock that would maintain to get a high expected return in the future. The study of Grundy and Martin (2001), demonstrate to momentums have significant minus beta subsequent to prices falls. The study argues that hedging this time-varying market disclosure produces stable momentum returns but Daniel et al. (1998) show that using betas in real time does not avoid the crashes. (Jegadeesh \& Titman, 2001, 2002) document the significance of momentum profitability after the primary discovery of momentum. Rouwenhorst (1998), finds momentum payoffs to be considerably positive in twelve other countries examined in his study. The strength of momentum returns has created a variety of justifications, behavioral and risk-based as well.

Essential exceptions consist of Chordia and Shivakumar (2002) that discover that the change in momentum is based on the business cycle, Cooper et al. (2004), report the momentum live just into 'up' marketplace position. Stivers and Sun (2010), discover that Cross-Sectional Returns influence payoffs of momentum. For the resolution of an anomaly, this is essential to know about its origin. Various Authors, e.g., (Daniel et al. (1998); Hong and Stein (1999)) present a behavioral model that have foundation on the initiative that momentums profit occurs due to inherent biases that are why investor interpret information. On the other hand, it's early to eliminate the rational model and recommend that the profitability's of momentums strategy might be recompense for threat.

According to Lo and MacKinlay (1990) and others, note down that stock with the high (low) unrestricted future rate of return in nearby time periods are expected to contain high (low) apprehend rate of returns in the same periods. The positive average returns arise from momentum strategies although expected profits on stocks are stable overtime. Hodoshima, Garza-Gómez, and Kunimura (2000), document the association between risk and stocks return in Japanese equities market via using Cross Section regressions. It is evidenced that there is an insignificant relationship among return and risks as regressions apply on extra return. However, when regressions tests are applied individually on optimistic and pessimistic return subsequently short terms association among return and risk have been reported.

Sukkur IBA Journal of Management and Business | Volume 4 No. 1 January - June 2017 @ Sukkur IBA University 
Strong positive average returns and the sharp ratio of momentum strategies are interposed by rare crashes. Brunnermeier, Nagel, and Pedersen (2008), state that negative returns are definite and determined. According to Cooper et al. (2004) and Stivers and Sun (2010), momentum premium falls when there is the situation of negativity state in previous three years and the market volatility is high when the momentum premium is high. Cooper et al. (2004), recommend behavioral justification for this evidence that reliable momentum performing unsuccessfully throughout market recovers when others are time as well if assets are mispriced.

\section{Data and Methodology}

The current study aims to explore the impact of market volatility on momentum profits in Pakistan. This study uses monthly and daily prices of 80 companies listed on Karachi Stock Exchange for the period of 2003-2015. The reason for using 80 companies is that only a few companies are frequently traded in the market, so large sample leads to the selection of inactive companies. Wang and $\mathrm{Xu}$ (2015), examine the momentum predictability and investigate market volatility as a forecaster of momentum profits.

Wang and $\mathrm{Xu}$ (2015), explore volatility as a predictor of momentum payoffs. Market volatility put in significant predictive influence in down market. Market volatility and markets state control many other variables and endow with the most vigorous depiction of the time-varying momentum earnings. Secondly, the study reports loser-centered predictability. The loser stocks generally have comparatively high earnings following volatile down market.

Wang and $\mathrm{Xu}$ (2015), investigate the predictive benefits on the market volatility intended for the profitability of momentum. Wang and $\mathrm{Xu}$ (2015), reveal that the volatility has a strong influence towards predict momentum payoff. Distinct business cycle along with variables of market state, report the significant influence of the market volatility on momentum sorted portfolio. The forecasting role of the market volatility continues along with market state and variables of the business cycle. Just market state persists in reporting forecasting force for momentum effectiveness.

The sample consists of companies from Non-Financial Sector. The motive to study just Non-Financial Sector is that in the case of financial sector accounting year closes at December in Non-Financial Sector, accounting period closes down in June generally. Moreover, the capital structures of the financial and non-financial sector are different. Monthly and daily stock prices have been taken from Karachi Stock Exchange. T-bill and Government bonds are taken from International Financial Statistics of IMF.

The companies are listed in various sectors that include Automobile and Parts, Beverages, Chemicals, Construction and Materials, Electricity, Fixed Line Telecommunication, Food Producers, Gas Water and Multi-utilities, General Industrials, Health Care Equipment and Services, Household Goods, Industrial

Sukkur IBA Journal of Management and Business | Volume 4 No. 1 January - June 2017 @ Sukkur IBA University 
Engineering, Industrial metals and Mining, Oil and Gas. This study uses time series regression based on OLS estimation technique.

This study is based on variables that include state of the market, volatility of market plus variables of the business cycle. Market volatility includes Vol+ and a Vol- and business cycle variable includes TERM, TERM2, and Yield. TERM is the difference of Treasury bill rate and Government bonds rates. Momentum is the difference between winner and loser. Momentum payoff is dependent variable and Market State, volatility of market and variables of the business cycle are independent variables. Secondly, this study regress Winner and Loser portfolios return on market state, market volatility and variables of the businesses cycle in perspective towards loser and winner (relative to the market) and loser and winner (adjusted by market).Then, dispersions of stock returns (RD1-3) is used to explore the impact of cross-sectional variation on momentum profit. RD1-3 is the three-month moving average of the cross-sectional standard deviation of return and it is taken as an independent variable. Finally, momentum payoffs are regressed on market state, market volatility and business cycle variables in UP and DOWN markets.

The various econometric models used in the study are explained as under:

\subsection{Market State and Volatility}

The role of market and volatility in explaining return is examined by using following equation:

Where,

Eq. (1)

$$
\text { MOM } t=\alpha 0+\alpha 1 M K T t+\alpha 2 \text { Volt }
$$

MOM is the momentum payoffs of month's t. For calculating momentum, the stock is categorized in the portfolio on the base of past return. The time of ranking is as of whereas portfolios with lowest past returns are defined as loser portfolios. The portfolios with the top earlier period returns are defined as winner portfolios. Momentum payoffs are the difference of the return between the winner and loser portfolio.

It is further added that momentum portfolio returns are a difference of returns of winner and loser portfolio comprising 40 stocks, each separated by using median. The robustness of results has also been tested by findings momentum returns as the difference of extreme quartile.

MKTt=market return at month $\mathrm{t}$.

Volt=volatility of the market at time $\mathrm{t}$ captured by the standard deviation of returns last six months returns.

Sukkur IBA Journal of Management and Business | Volume 4 No. 1 January - June 2017 @ Sukkur IBA University 
There is a possibility that response of the momentum return may be different in high and low return period. The same possibility is explained by using following equation:

Where,

Eq. (2)

$$
\mathrm{MOM} \mathrm{t}=\alpha 0+\alpha 1 \mathrm{MKT}+\alpha 2 \mathrm{Vol}++\alpha 3 \mathrm{Vol}-
$$

Vol+ $=$ volatility if lagged six-month market returns are positive otherwise zero.

Vol- = volatility of the lagged six market returns are negative otherwise zero.

\subsection{Market state, market volatility, and business cycles}

The study further adds the function of business's cycles in determining profits of momentum. The same has been investigated as following:

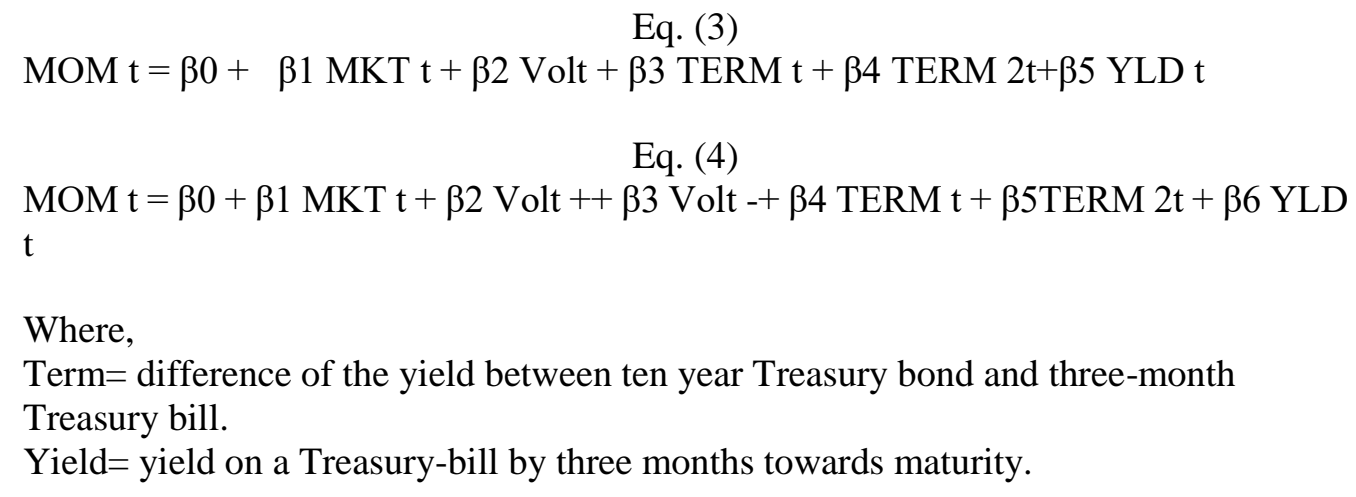

Where,

Term $=$ difference of the yield between ten year Treasury bond and three-month Treasury bill.

Yield= yield on a Treasury-bill by three months towards maturity.

\subsection{Discussion}

The robustness of the model has also been tested by using market adjusted model. Hence examination of winner and loser has been calculated by subtracting market returns from the winners and losers portfolios:

$$
\begin{gathered}
\text { Eq. (5) } \\
\begin{array}{c}
\text { LoserMKT } \mathrm{t}=\beta 0+\beta 1 \text { TERM } \mathrm{t}+\beta 2 \text { TERM } 2 \mathrm{t}+\beta 3 \text { YLD } \mathrm{t}+\beta 4 \text { MKT } \mathrm{t}+\beta 5 \text { Volt } \\
\text { Eq. (6) } \\
\text { WinnerMKT } \mathrm{t}=\beta 0+\beta 1 \text { TERM } \mathrm{t}+\beta 2 \text { TERM } 2 \mathrm{t}+\beta 3 \text { YLD } \mathrm{t}+\beta 4 \text { MKT } \mathrm{t}+\beta 5 \text { Volt }
\end{array}
\end{gathered}
$$

The basic model is also investigated in up and down markets as given below:

$$
\begin{gathered}
\text { Eq. (7) } \\
\text { Loser } \mathrm{t}=\beta 0+\beta 1 \text { TERM } \mathrm{t}+\beta 2 \text { TERM } 2 \mathrm{t}+\beta 3 \text { YLD } \mathrm{t}+\beta 4 \text { MKT } \mathrm{t}+\beta 5 \text { Volt }++\beta 6 \\
\text { Volt }- \\
\text { Eq. (8) }
\end{gathered}
$$




$$
\begin{aligned}
& \text { Winner } \mathrm{t}=\beta 0+\beta 1 \text { TERM } \mathrm{t}+\beta 2 \text { TERM } 2 \mathrm{t}+\beta 3 \text { YLD } \mathrm{t}+\beta 4 \text { MKT } \mathrm{t}+\beta 5 \text { Volt }++ \\
& \beta 6 \text { Volt - }
\end{aligned}
$$

The behavior in up and down market is explained by using following model:

Eq. (9)

$$
\begin{gathered}
\text { LoserMKT } \mathrm{t}=\beta 0+\beta 1 \text { TERM } \mathrm{t}+\underset{+}{\beta 2 \text { TERM } 2 \mathrm{t}+\beta 3 \text { YLD } \mathrm{t}+}+\beta 4 \text { MKT } \mathrm{t}+\beta 5 \text { Volt }- \\
++\beta 6 \text { Volt }-
\end{gathered}
$$

Eq. (10)

WinnerMKT $\mathrm{t}=\beta 0+\beta 1$ TERM $\mathrm{t}+\beta 2$ TERM $2 \mathrm{t}+\beta 3$ YLD $\mathrm{t}+\beta 4$ MKT $\mathrm{t}+\beta 5$ Volt $++\beta 6$ Volt -

It is further added that square of the term is added to see the possibility of non-linear behavior.

\subsection{Potential explanations: Return dispersion}

Literature provides that market's volatility measuring the time-series variant in the total marketplace and returns dispersal measuring the cross-sectional variant in stock return. So, the phenomenon is also explained by using:

Eq. (11)

$\mathrm{MOMt}=\alpha 0+\alpha 1 \mathrm{RD} 1-3$

Eq. (12)

$\mathrm{MOMt}=\alpha 0+\alpha 1 \mathrm{MKT}+\alpha 2 \mathrm{Vol}+\alpha 3 \mathrm{RD} 1-3$

The impact of the business cycle on momentum in the presence of time series variation and cross-sectional variation is examined by using following regression method:

Eq. (13)

$$
\begin{aligned}
& \mathrm{MOMt}=\beta 0+\beta 1 \text { TERM } \mathrm{t}+\beta 2 \text { TERM } 2 \mathrm{t}+\beta 3 \text { YLD } \mathrm{t}+\beta 4 \text { MKT } \mathrm{t}+\beta 5 \text { Volt }+\beta 6 \\
& \text { RD1-3 }
\end{aligned}
$$

Eq. (14)

$$
\begin{gathered}
\text { MOMt }=\beta 0+\beta 1 \text { TERM } \mathrm{t}+\beta 2 \text { TERM } 2 \mathrm{t}+\beta 3 \text { YLD } \mathrm{t}+\beta 4 \text { MKT } \mathrm{t}+\beta 5 \text { Volt }++\beta 6 \\
\text { Volt }-+\beta 7 \text { RD } 1-3
\end{gathered}
$$

Where,

RD1-3= three months moving an average of the cross-sectional standard deviation of the returns of the portfolio.

Sukkur IBA Journal of Management and Business | Volume 4 No. 1 January - June 2017 @ Sukkur IBA University 


\section{Results and Discussion}

\section{Impact of Market Return and Volatility on Momentum Profit}

Table 4.1.1 reports the results of regression analysis used to study the impact of volatility and market returns on momentum profits. Momentum payoff is taken as dependent variable and market state, market volatility (Vol, Vol+, and Vol-) are independent variables. This study uses the different structure of momentum portfolio for robustness checks. For each regression, intercepts, beta coefficients, t-statistics (in parentheses), adjusted R-squares and Prob(Wald F-statistic) are reported. Results of stepwise regressions are presented below:

Table 4.1.1: Impact of Market Return and Volatility on Momentum Profit

\begin{tabular}{|c|c|c|c|c|c|c|}
\hline $\mathrm{C}$ & MKT & Vol & Vol+ & Vol- & Adj-R ${ }^{2}$ & $\mathrm{P}$ (Wald F-stat) \\
\hline \multicolumn{7}{|c|}{ I. Market state and volatility (50\%) } \\
\hline $0.065^{* *}$ & $-0.127 * *$ & $-0.154 * *$ & & & 0.0216 & 0.0168 \\
\hline (8.122) & $(-2.648)$ & $(-1.826)$ & & & & \\
\hline $0.073^{*}$ & -0.110 & & $-0.345^{*}$ & $-0.150 *$ & 0.0239 & 0.0017 \\
\hline (8.518) & $(-2.155)$ & & $(-2.921)$ & $(-2.036)$ & & \\
\hline \multicolumn{7}{|c|}{ II. Market state and volatility (25\%) } \\
\hline $0.103 *$ & $-0.213 *$ & $-2.237^{*}$ & & & 0.0251 & 0.0061 \\
\hline$(8.041)$ & $(-3.059)$ & $(-1.540)$ & & & & \\
\hline $0.117 *$ & $-0.185^{*}$ & & $-0.564 *$ & $-0.229 *$ & 0.0293 & 0.0006 \\
\hline$(9.047)$ & $(-2.481)$ & & $(-3.038)$ & $(-1.765)$ & & \\
\hline
\end{tabular}

In I phase momentum is calculated on the difference between $50 \%$ winners and $50 \%$ losers and momentum payoff is regressed on market return and volatility. Market premium is significant and negative whereas market volatility is found negatively influencing momentum profits. However, when volatility is divided into volatility in the positive market and volatility in the negative market both are significantly and negatively influencing momentum profits. The results are in line with earlier studies that high volatility is followed by low momentum profits.

The same process is repeated for II phase, momentum payoffs calculated by using the difference of $25 \%$ winners and 25\% losers. Both MKT and Vol are significant, indicating that both variables have the capability to forecast momentum profits. Table 4.1.1presents the results of regressions with market state and market volatility as the independent variable. Here, the momentum payoff is calculated at $50 \%$ and $25 \%$ to test the robustness of results. The model is found to be fit because F- Statistics are significant.

This study does not contradict the predictive power of the market state. This view is that market volatility and market state when combined together; provide a useful indicator of market conditions. The predictive power of market volatility is more evident in down markets. Although $\mathrm{Vol}+$ and Vol- both have negative signs, Vol- is

Sukkur IBA Journal of Management and Business | Volume 4 No. 1 January - June 2017 @ Sukkur IBA University 
dominant in terms of the magnitudes of the coefficient and the t-statistic. The explanatory power of the model remains low as all other factors that influence the returns have not been included in the model because the objective of the study is sole to explore the relationship between volatility and momentum. In both test, at $50 \%$ and $25 \%$, results are same indicating the robustness of results.

\section{Impact of Market State and Market Volatility, and Business Cycles on Momentum}

Table 4.1.2 reports the results of regression analysis conducted to explore the impact of market state, volatility and business cycle on market return. When momentum payoffs are taken as dependent variable and market state, market volatility and business cycle variables (TERM, TERM2, and YLD) are independent variables. This study uses alternative measures of momentum profitability for robustness checks. For each regression, intercepts, beta coefficients, and robust t-statistics (in parentheses), adjusted R-squares and Prob (Wald F-statistic) are reported. Results of regression are presented below:

\begin{tabular}{|c|c|c|c|c|c|c|c|}
\hline $\mathrm{C}$ & MKT & Vol & TERM & TERM $^{2}$ & YLD & Adj-R ${ }^{2}$ & $\begin{array}{l}\mathrm{P}(\mathrm{W} \text { ald F- } \\
\text { stat })\end{array}$ \\
\hline \multicolumn{8}{|c|}{ I. Regular momentum construction (50\%) } \\
\hline $0.059 * *$ & - & - & - & & 0.114 & 0.0107 & 0.0320 \\
\hline (3.986) & $\begin{array}{l}0.121 * * \\
(-2.327)\end{array}$ & $\begin{array}{l}0.168 * * \\
(-1.967)\end{array}$ & $\begin{array}{l}0.171 * * \\
(-0.406)\end{array}$ & & $(0.711)$ & & \\
\hline $0.058^{* *}$ & - & - & - & $7.176^{* *}$ & $0.128^{* *}$ & 0.0036 & 0.0291 \\
\hline (2.824) & $\begin{array}{l}0.121 * * \\
(-2.316)\end{array}$ & $\begin{array}{l}0.170 * * \\
(-2.046)\end{array}$ & $\begin{array}{l}0.202 * * \\
(-0.543)\end{array}$ & $(0.159)$ & $(0.620)$ & & \\
\hline \multicolumn{8}{|c|}{ II. Regular momentum construction (25\%) } \\
\hline $0.097 * *$ & - & - & - & & 0.111 & 0.0119 & 0.0183 \\
\hline (4.128) & $\begin{array}{l}0.207 * * \\
(-2.826)\end{array}$ & $\begin{array}{l}0.247 * * \\
(-1.571)\end{array}$ & $\begin{array}{l}0.051 * * \\
(-0.086)\end{array}$ & & $(0.410)$ & & \\
\hline $0.089 * *$ & - & - & - & 42.633 & 0.194 & 0.0059 & 0.0220 \\
\hline$(2.823)$ & $\begin{array}{l}0.207 * * \\
(-2.809)\end{array}$ & $\begin{array}{l}0.257 * * \\
(-1.638)\end{array}$ & $\begin{array}{l}0.234 * * \\
(-0.499)\end{array}$ & $(0.622)$ & $(0.579)$ & & \\
\hline
\end{tabular}

The results in section I of table 4.1.2 indicate that market returns and market volatility have a significant influence on momentum payoffs. The signs of market state and market volatility are negative and significant indicating the momentum payoffs are inversely related to market returns and market volatility. It means when market returns increase or volatility increases, momentum payoff decrease. Business cycle effect measured by term and yield is not found significant. Similarly, non-linearity has not been observed regarding the term. The robustness of the model has also been tested by using momentum profits measured by using the difference of top $25 \%$ winners and top $25 \%$ losers. The market state is found to effect significantly whereas volatility has same sign but is now significant at approximately $90 \%$ level of significance.

Sukkur IBA Journal of Management and Business | Volume 4 No. 1 January - June 2017 @ Sukkur IBA University 
Table 4.1.2 also presents the results of regressions analysis regarding the impact of business cycle variables, market volatility, and market state on momentum profitability. The robustness of the basic results has also been tested by using the return of momentum profit comprising of the difference of 50\% stock or top 25\% stocks of winners and losers portfolios. Table 4.1.2 examine the rate of the macroeconomic variables in explaining momentum. The explanatory power of the model is low as all other factors that influence the returns have not been included in the model because the objective of the study is exclusive to explore the relationship between volatility and momentum. In both conditions, at $50 \%$ and $25 \%$ results are same. The model is found to be fit.

The results indicate that market state is significant and negative which is consistent with results reported in table 4.1.1 and 4.1.2. Market volatility is negative but insignificant, however, volatility in the positive market has significant influence whereas volatility in the negative market has an insignificant impact on momentum payoffs. The yield has significant and positive effect whereas term and terms are found insignificantly influencing momentum payoffs. The results are found robust when momentum payoffs are calculated by using the difference of top $25 \%$ winners and top $25 \%$ losers. The model is found fit the explanatory power of the model is found low as model considers only volatility and the business cycle and ignores fundamentals. The results are to focus on the volatility and momentum dynamics. In sum, both Table 4.1.1 and Table 4.1.2 show that market volatility has robust predictive power in the presence of market state and macroeconomic variables. This study also notices that in all cases the predictive power of market volatility is more pronounced in down markets.

\section{Impact of Market State and Market Volatility and Business Cycles on Market Adjusted Momentum Payoff}

Table 4.1.3 reports the results of regression analysis when market adjusted momentum payoff are taken as dependent variable and market state, market volatility and business cycle variables (TERM, TERM2, and YLD) are independent variables. This study uses alternative measures of momentum profitability for robustness test. Momentum adjusted portfolio is calculated by subtracting market returns from momentum returns. For each regression, intercepts, beta coefficients, robust t-statistics (in parentheses), adjusted R-squares and Prob (Wald F-statistic) are reported. Results of regression are presented below: 
Table 4.1.3: Impact of Market State and Market Volatility and Business Cycles on Market

\begin{tabular}{|c|c|c|c|c|c|c|c|c|c|}
\hline & & & & & entum & off & & & \\
\hline $\mathrm{C}$ & TERM & TERM $^{2}$ & YLD & MKT & Vol & Vol+ & Vol- & Adj-R ${ }^{2}$ & $\begin{array}{l}\text { P(Wald } \\
\text { F-stat) }\end{array}$ \\
\hline$I . M O M-$ & isted $\left(50^{\circ}\right.$ & & & & & & & & \\
\hline $0.038^{*}$ & & & & $-0.139 *$ & $-0.018 *$ & & & 0.0147 & 0.0110 \\
\hline (3.705) & & & & $(-2.873)$ & $(-0.143)$ & & & & \\
\hline $0.053^{*}$ & & & & $-0.108 *$ & & $-0.371 *$ & $-0.010^{*}$ & 0.0369 & 0.0001 \\
\hline (5.450) & & & & $(-2.032)$ & & $(-2.783)$ & $(-0.124)$ & & \\
\hline$-0.006 *$ & $0.336^{*}$ & & $0.688^{*}$ & $-0.105^{*}$ & $-0.064 *$ & & & 0.0602 & 0.0000 \\
\hline$(-0.340)$ & $(0.661)$ & & (3.609) & $(-2.026)$ & $(-0.640)$ & & & & \\
\hline$-0.001 *$ & $0.462^{*}$ & - & 0.631 & $-0.105 *$ & $-0.057 *$ & & & 0.0546 & 0.0000 \\
\hline$(-0.028)$ & (1.067) & $\begin{array}{l}29.397^{*} \\
(-0.601)\end{array}$ & (2.702) & $(-2.030)$ & $(-0.593)$ & & & & \\
\hline II.MOM & usted ( 25 & & & & & & & & \\
\hline $0.076^{*}$ & & & & $-0.225^{*}$ & $-0.100 *$ & & & 0.0199 & 0.0069 \\
\hline$(5.270)$ & & & & $(-3.190)$ & $(-0.525)$ & & & & \\
\hline $0.098^{*}$ & & & & $-0.183^{*}$ & & $-0.590 *$ & $-0.090 *$ & 0.0371 & 0.0003 \\
\hline (7.299) & & & & $(-2.373)$ & & $(-3.095)$ & $(-0.661)$ & & \\
\hline $0.032 *$ & $0.456^{*}$ & & $0.686^{*}$ & $-0.191 *$ & $-0.143 *$ & & & 0.0306 & 0.0018 \\
\hline$(1.262)$ & $(0.725)$ & & (2.362) & $(-2.586)$ & $(-0.843)$ & & & & \\
\hline $0.031^{*}$ & $0.430^{*}$ & 6.060 & $0.697 *$ & $-0.191 *$ & $-0.144 *$ & & & 0.0236 & 0.0045 \\
\hline (0.922) & $(0.817)$ & $(0.086)$ & (1.954) & $(-2.577)$ & $(-0.860)$ & & & & \\
\hline
\end{tabular}

Table 4.1.3 reports results of regressions analyses the same as Table 4.1.1 and Table 4.1.2 and further add some business cycle variables the same as Table 4.1.2. This table uses market, momentum profit and market volatility, market state, and the business cycle. The purpose is the same to establish the robustness of the basic results for profits constituted by using top $50 \%$ and $25 \%$ stocks from winners and losers. The phase I and II results indicate that market state and market volatility have a significant influence on adjusted momentum payoffs. The signs of market state and market volatility are negative and significant indicating the momentum payoffs are inversely related to market returns and market volatility. It means when market returns increase or volatility increases, momentum payoff decreases. Business cycle effect measured by term and yield is not found significant. Similarly, non-linearity has not been observed regarding the term. The model is found a fit.

\section{Impact of Market State and Market Volatility, and Business Cycles on Market Adjusted Loser Portfolio}

Table 4.2.1 report the impact of market state, market volatility, and business cycle variables on market adjusted lower returns. The definition of these variables is the same as explained earlier. Portfolio returns are adjusted by the market. The sample period is from 2003-2015 and study report intercepts, regression coefficients, robust t-statistics

Sukkur IBA Journal of Management and Business | Volume 4 No. 1 January - June 2017 @ Sukkur IBA University 
(in parentheses), adjusted R-squares and Prob(Wald F-statistic). Results are given below:

Table 4.2.1: Impact of Market State and Market Volatility, and Business Cycles on Market

\begin{tabular}{|c|c|c|c|c|c|c|c|c|c|}
\hline $\mathrm{C}$ & TERM & TERM $^{2}$ & YLD & MKT & Vol & Vol+ & Vol- & $\begin{array}{l}\text { Adj- } \\
\mathrm{R}^{2}\end{array}$ & $\begin{array}{l}\text { P(Wald } \\
\text { F-stat) }\end{array}$ \\
\hline \multicolumn{10}{|c|}{ Loser (adjusted by market) $50 \%$} \\
\hline$-0.025^{*}$ & & & & $-0.816^{*}$ & $-0.009^{*}$ & & & 0.3536 & 0 \\
\hline$(-1.624)$ & & & & $(-10.129)$ & $(-0.05)$ & & & & \\
\hline$-0.023^{*}$ & & & & $-0.813^{*}$ & & $\overline{-} .046^{*}$ & $-0.008 *$ & 0.3491 & 0 \\
\hline$(-1.334)$ & & & & $(-9.894)$ & & $(-0.19)$ & $(-0.04)$ & & \\
\hline $0.018^{*}$ & $-1.158^{*}$ & & $-0.578^{*}$ & $-0.842 *$ & $0.006^{*}$ & & & 0.3609 & 0 \\
\hline$(0.638)$ & $(-0.945)$ & & $(-1.587)$ & $(-10.235)$ & $(0.039)$ & & & & \\
\hline$-0.011^{*}$ & $-1.875^{*}$ & $166.474 *$ & $-0.257^{*}$ & $-0.842 *$ & $-0.032 *$ & & & 0.3713 & 0 \\
\hline$(-0.359)$ & $(-1.810)$ & $(1.581)$ & $(-0.623)$ & $(-10.577)$ & $(-0.19)$ & & & & \\
\hline \multicolumn{10}{|c|}{ Loser (adjusted by market) 25\% } \\
\hline$-0.040^{*}$ & & & & $-0.755^{*}$ & $-0.011^{*}$ & & & 0.2561 & 0 \\
\hline$(-2.326)$ & & & & $(-8.238)$ & $(-0.05)$ & & & & \\
\hline$-0.0411^{*}$ & & & & $-0.756 *$ & & $0.004 *$ & $-0.011 *$ & 0.2508 & 0 \\
\hline$(-2.112)$ & & & & $(-8.255)$ & & $(0.015)$ & $(-0.05)$ & & \\
\hline $0.001 *$ & $-1.105^{*}$ & & $-0.562 *$ & $-0.780^{*}$ & $0.005 *$ & & & 0.2588 & 0 \\
\hline$(0.022)$ & $(-0.795$ & & $(-1.422)$ & -8.312 & (0.023) & & & & \\
\hline$-0.011^{*}$ & $-1.875^{*}$ & $166.474^{*}$ & $-0.257^{*}$ & $-0.842 *$ & $-0.032 *$ & & & 0.3713 & 0 \\
\hline$(-0.359)$ & $(-1.810)$ & $(1.581)$ & $(-0.623)$ & $(-10.577)$ & $(-0.19)$ & & & & \\
\hline
\end{tabular}

Table 4.2.1 present that market state has a significant negative relationship with market adjusted has loser portfolios. Market increase loser returns decrease. The results are robust for loser portfolios capturing of lower 50\% stocks as well as lowest $25 \%$ stocks. Volatility significant in all cases but the behavior of volatility is same for positive and negative market state.

Moreover, its impact does not change with the change in the computation of loser portfolio. The term is found significant at $\alpha=0.1$. As term spread increase, returns of loser portfolio decrease. The explanatory power of the model remains $25 \%$ to $37 \%$ and model is found correctly specified. The behavior of the variable is consistent for market adjusted loser portfolio irrespective of the fact that these are found by using $50 \%$ loser stocks or $25 \%$ loser stocks. 


\section{Impact of Market State and Market Volatility, and Business Cycles on Market Adjusted Winner Portfolio}

The study regress market state, market volatility, and business cycle variables on market adjusted winner portfolio returns. Portfolio returns are adjusted for the market return. Results are given below in table 4.2.2.

Table 4.2.2: Impact of Market State and Market Volatility, and Business Cycles on Market

\begin{tabular}{|c|c|c|c|c|c|c|c|c|c|}
\hline $\mathrm{C}$ & TERM & TERM $^{2}$ & YLD & MKT & Vol & Vol+ & Vol- & $\begin{array}{l}\text { Adj- } \\
R^{2}\end{array}$ & $\begin{array}{l}\text { P(Wald } \\
\text { F-stat) }\end{array}$ \\
\hline \multicolumn{10}{|c|}{ Winner (adjusted by market) $50 \%$} \\
\hline $0.040^{*}$ & & & & $-0.943^{*}$ & $-0.163 *$ & & & 0.4700 & 0 \\
\hline$(3.154)$ & & & & $(-11.14)$ & $(-1.173)$ & & & & \\
\hline $0.050 *$ & & & & $-0.923 *$ & & $-0.391 *$ & $-0.158^{*}$ & 0.4707 & 0 \\
\hline (2.943) & & & & $(-10.61)$ & & $(-1.46)$ & $(-0.99)$ & & \\
\hline $0.077^{*}$ & $-1.330^{*}$ & & $-0.464 *$ & $-0.963 *$ & $-0.162 *$ & & & 0.4756 & 0 \\
\hline$(3.270)$ & $(-1.229)$ & & $(-1.441)$ & $(-11.54)$ & $(-1.162)$ & & & & \\
\hline $0.047 *$ & $-2.077^{*}$ & $173.650 *$ & $-0.129 *$ & $-0.963 *$ & $-0.202^{*}$ & & & 0.4877 & 0 \\
\hline$(2.042)$ & $(-2.261)$ & $(1.768)$ & $(-0.370)$ & $(-11.77)$ & $(-1.408)$ & & & & \\
\hline \multicolumn{10}{|c|}{ Winner (adjusted by market) $25 \%$} \\
\hline $0.062^{*}$ & & & & $-0.968 *$ & $-0.247 *$ & & & 0.3882 & 0 \\
\hline$(4.238)$ & & & & $(-10.21)$ & $(-1.705)$ & & & & \\
\hline $0.0762 *$ & & & & $-0.941 *$ & & $-0.560 *$ & $-0.240^{*}$ & 0.3903 & 0 \\
\hline (3.837) & & & & $(-9.322)$ & & $(-1.81)$ & $(-1.47)$ & & \\
\hline $0.097^{*}$ & $-1.156^{*}$ & & $-0.451^{*}$ & $-0.988^{*}$ & $-0.242 *$ & & & 0.3882 & 0 \\
\hline (3.497) & $(-0.848)$ & & $(-1.186)$ & $(-10.81)$ & $(-1.579)$ & & & & \\
\hline $0.061 *$ & $-2.063^{*}$ & $210.556^{*}$ & $-0.044^{*}$ & $-0.988 *$ & $-0.291 *$ & & & 0.4020 & 0 \\
\hline (2.046) & $(-1.790)$ & (1.598) & $(-0.102)$ & $(-11.05)$ & $(-1.778)$ & & & & \\
\hline
\end{tabular}

Table 4.2.2 exhibits that market returns have a significant and negative impact on returns of the market adjusted portfolio. Volatility is significant and insignificant irrespective of the fact that the portfolio compares of 50\% stocks or $25 \%$ stocks. In the positive state of the market impact of $\mathrm{Vol}+$ is negative and lower on winner portfolio comprising top $25 \%$ stock and thus impact is increased and significant at $90 \%$ level of significance for a portfolio comprising top $25 \%$ stock. The same tendency is observed of Vol- but results remain insignificant. It leads to the idea that Vol may be influencing the extreme winners. From business cycles variables, yield exhibits an insignificant influence whereas yield is significant and negative for winner portfolio comprising top $25 \%$, but this relationship weakens for $25 \%$ winners stocks. However, no non-linearity is observed in the behavior of the terms. The explanatory power of the model ranges from $38 \%$ to $49 \%$. The results indicate that volatile markets forecast low returns on winners stocks.

Sukkur IBA Journal of Management and Business | Volume 4 No. 1 January - June 2017 @ Sukkur IBA University 


\section{Impact of Cross Sectional Variation or Time Variation on Momentum Profits}

Table 4.3.1 reports the results of regression analysis. When momentum payoffs are taken as the dependent variable and market state, market volatility, business cycle variables (TERM, TERM2, and YLD) and return dispersion (RD1-3) are independent variables. This study examines whether stock return dispersion (RD1-3); can absorb the predictive power of market volatility on momentum profitability. The repressors MKT, Vol, Vol+, and Vol- are the same as explained earlier. Results for intercepts, regression coefficients, and robust t-statistics (in parentheses), adjusted R-squares and Prob (Wald F-statistic) are reported below:

\begin{tabular}{|c|c|c|c|c|c|c|c|c|c|c|}
\hline $\mathrm{C}$ & TERM & TERM $^{2}$ & YLD & MKT & Vol & Vol+ & Vol- & $\mathrm{RD}_{1-3}$ & $\begin{array}{l}\text { Adj- } \\
R^{2}\end{array}$ & $\begin{array}{l}\mathrm{P}(\text { Wald F- } \\
\text { stat) }\end{array}$ \\
\hline \multicolumn{11}{|c|}{ Return dispersion 50\% } \\
\hline $0.121 * *$ & & & & & & & & $\overline{2} .926 * *$ & 0.0537 & 0.0858 \\
\hline (2.929) & & & & & & & & $(-1.73)$ & & \\
\hline $0.131 * *$ & & & & - & - & & & - & 0.0733 & 0.0186 \\
\hline (3.204) & & & & $\begin{array}{l}0.121 * * \\
(-2.58)\end{array}$ & $\begin{array}{l}0.149 * * \\
(-1.96)\end{array}$ & & & $\begin{array}{l}2.856^{* *} \\
(-1.76)\end{array}$ & & \\
\hline 0.131 ** & - & & $0.017 * *$ & & & & & & 0.0605 & 0.0558 \\
\hline (2.577) & $\begin{array}{l}0.1611^{* * 2} \\
(-0.486)\end{array}$ & & $(0.086)$ & $\begin{array}{l}0.120^{\text {N* }} \\
(-2.39)\end{array}$ & $\begin{array}{l}0.155^{* *} \\
(-1.957)\end{array}$ & & & $\begin{array}{l}2.829^{* * *} \\
(-1.67)\end{array}$ & & \\
\hline $0.132 * *$ & & $-7.451 * *$ & $0.002 * *$ & - & - & & & - & 0.0537 & 0.0560 \\
\hline (2.319) & $\begin{array}{l}0.129 * * \\
(-0.468)\end{array}$ & $(-0.176)$ & $(0.008)$ & $\begin{array}{l}0.120 \text { *** } \\
(-2.38)\end{array}$ & $\begin{array}{l}0.153 * * \\
(-1.98)\end{array}$ & & & $\begin{array}{l}2.838 * * \\
(-1.65)\end{array}$ & & \\
\hline $0.139 * *$ & & & & & & - & - & - & 0.0463 & 0.0185 \\
\hline (2.713) & $\begin{array}{l}0.249 * * \\
(-0.70)\end{array}$ & & $\begin{array}{l}0.022 * * \\
(-0.107)\end{array}$ & & & $\begin{array}{l}0.359 * * \\
(-2.54)\end{array}$ & $\begin{array}{l}0.157 * * \\
-2.034\end{array}$ & $\begin{array}{l}2.748 * * \\
(-1.58)\end{array}$ & & \\
\hline $\begin{array}{l}0.140^{*} \\
(2.415)\end{array}$ & $\begin{array}{l}-0.239^{*} \\
(-0.74)\end{array}$ & $\begin{array}{l}-2.251^{*} \\
(-0.050)\end{array}$ & $\begin{array}{l}-0.026^{*} \\
(-0.103)\end{array}$ & & & $\begin{array}{l}-0.358^{*} \\
(-2.56)\end{array}$ & $\begin{array}{l}-0.157^{*} \\
(-2.083)\end{array}$ & $\begin{array}{l}-2.751^{*} \\
(-1.54)\end{array}$ & 0.0393 & 0.0089 \\
\hline \multicolumn{11}{|c|}{ Return dispersion $25 \%$} \\
\hline $\begin{array}{l}0.183^{*} \\
(2.903)\end{array}$ & & & & & & & & $\begin{array}{l}-4.220^{*} \\
(-1.64)\end{array}$ & 0.0445 & 0.1031 \\
\hline $\begin{array}{l}0.199^{*} \\
(3.165)\end{array}$ & & & & $\begin{array}{l}-0.205^{*} \\
(-2.985)\end{array}$ & $\begin{array}{l}-0.229 * \\
(-1.64)\end{array}$ & & & $\begin{array}{l}-4.104 * \\
(-1.664)\end{array}$ & 0.0675 & 0.0104 \\
\hline $0.201 * *$ & - & & - & - & - & & & - & 0.0540 & 0.0377 \\
\hline$(2.575)$ & $\begin{array}{l}0.036 * * \\
(-0.065)\end{array}$ & & $\begin{array}{l}0.030^{* *} \\
(-0.091)\end{array}$ & $\begin{array}{l}0.206 * * \\
(-2.902)\end{array}$ & $\begin{array}{l}0.228 * * \\
(-1.54)\end{array}$ & & & $\begin{array}{l}4.123 * * \\
(-1.607)\end{array}$ & & \\
\hline $0.197 * *$ & - & $21.508 * *$ & $0.012 * *$ & - & - & & & - & 0.0474 & 0.0665 \\
\hline$(2.231)$ & $\begin{array}{l}0.128 * * \\
(-0.316)\end{array}$ & $(0.286)$ & $(0.029)$ & $\begin{array}{l}0.206 * * \\
(-2.890)\end{array}$ & $\begin{array}{l}0.233 * * \\
(-1.577)\end{array}$ & & & $\begin{array}{l}4.098 * * \\
(-1.552)\end{array}$ & & \\
\hline $0.218^{* *}$ & - & & - & & & - & - & -3.968 & 0.0392 & 0.0151 \\
\hline (2.724) & $\begin{array}{l}0.209 * * \\
(-0.370)\end{array}$ & & $\begin{array}{l}0.116^{* * *} \\
(-0.327)\end{array}$ & & & $\begin{array}{l}0.612 * * \\
(-2.732)\end{array}$ & $\begin{array}{l}0.230 * * \\
(-1.765)\end{array}$ & $(-1.497)$ & & \\
\hline $0.212 * *$ & - & $31.563 * *$ & - & & & & - & & 0.0328 & 0.0188 \\
\hline$(2.340)$ & $\begin{array}{l}0.349 * * \\
(-0.690)\end{array}$ & $(0.400)$ & $\begin{array}{l}0.057 * * \\
(-0.130)\end{array}$ & & & $\begin{array}{l}0.625^{* *} \\
(-2.818)\end{array}$ & $\begin{array}{l}0.237 * * \\
(-1.837)\end{array}$ & $\begin{array}{l}3.929 * * \\
(-1.430)\end{array}$ & & \\
\hline
\end{tabular}

Table 4.3.1; explores potential explanations for the predictive power of market volatility for momentum profitability. In this study, another variable the cross-sectional stock return dispersion proposed by (Stivers and Sun (2010)) is used. Stivers and Sun (2010) find that cross-sectional return dispersion negatively predicts momentum performance. Following them, in this study calculate the three-month moving average of the crosssectional standard deviation of the returns, denoted by RD1-3. While the two variables are highly correlated, market volatility and return dispersion are conceptually different.

Sukkur IBA Journal of Management and Business | Volume 4 No. 1 January - June 2017 @ Sukkur IBA University 
Market volatility measures time-series variation of the overall market return. Return dispersion measures the cross-sectional variation in stock returns is also found significant at $90 \%$ level of significance.

The results, reported in Table 4.8, confirm that RD1-3 has predictive power with the right sign. When used alone, it has a significant t-statistic of $90 \%$ level of significance. The adjusted R-square is $0.5 \%$. However, when MKT and Vol are included, the tstatistic of RD1-3 rises to -1.761 . Adding business cycle variables does not save the predictive power of RD1-3. Similarly, in the presence of $\mathrm{Vol}+$ and $\mathrm{Vol}-$, the significance of RD1-3 also decreases. Therefore, although market volatility is not correlated with return dispersion, some of the predictive power of market volatility is not derived from return dispersion. In this case, the explanatory power of the model remains generally low as all other factors that influence the returns have not been included in the model because the objective of the study is sole to explore the relationship between volatility and momentum. The results are found robust for different measures of return dispersion. The model is found to be fit because FStatistics is significant.

\section{Conclusion}

The purpose of this study is to explore the relationship between market volatility and momentum profitability by using KSE data. For this purpose, 80 companies are taken from 14 on- financial sector of KSE. The range of data is from 2003-2015. Momentum portfolios have been created by using top $25 \%$ and lowest $25 \%$ as well as top $50 \%$ and lowest $50 \%$. However, volatility is the dispersion, so it may be on the positive side or negative side. It may be different in positive market state and negative market state. The market does not work in isolation. The macroeconomic dynamics especially business cycle variables are influencing the market. All major variables explore in this study. According to Wang and $\mathrm{Xu}$ (2015), Volatility is a central indication in capital markets. The aim of this study is to check out the role of market volatility in characterizing time series variations in momentum payoffs and execute different tests and disclose a robust and significant relationship among market volatility and momentum. The tests create a broad summary of time varying momentum performance, exhibiting that the time series predictability of momentum is relatively changed from cumulative stock market predictability.

This study examines whether market volatility has explanatory power for momentum as well as this study executes different tests and the results show that there exists a robust relationship among market volatility and momentum. Market volatility and market state balance each other and both markets present a robust empirical description of the time variation in momentum payoffs. Their predictive power can be exploited to boost the momentum profitability. The challenge is how to realistically clarify why these variables predict momentum. The signs of market state and market volatility are negative and significant indicating the momentum payoffs are inversely related to

Sukkur IBA Journal of Management and Business | Volume 4 No. 1 January - June 2017 @ Sukkur IBA University 
market returns and market volatility. It means when market returns increase or volatility increases, momentum payoff decrease. Business cycle effect measured by term and yield is not found significant. Non-linearity has not been observed regarding the term. The market state is found to affect significantly.

Investors can earn excess returns on the basis of past market returns. These returns give an indication of the future movement in the company's stock returns. Investors can earn higher returns by investing in small companies. The negative relationship indicates that there is high volatility in the market. Its mean momentum returns will decrease in future. Investors should be taking into account that volatility is a leading indicator that the momentum strategy will be beneficial in the future. Momentum strategies plan according to market conditions.

With the changing conditions of the market business cycle cannot be overlooked. During the period of the high rate of interest momentum profits will decrease. During the period of low-interest rate momentum profits will rise. When going to making a decision then consider that during on which side average yield rate of return is more. The market, business cycle, and volatility depend on investor's momentum strategies. The benefits of momentum strategy on that time will be purposeful when momentum profits will be increased. The things that decrease momentum profit, on that time momentum strategy should not adopt. If volatility increases then enter into winner portfolio strategies.

The study recommends that investors should devise investment and momentum strategies on the basis of the volatility of stocks and business cycle variables. As volatile and stable stock have different market returns, so efficient market hypothesis can be formed. In the absence of significant factors, market returns will be low that may lead to a sub-optimal decision while evaluating new projects. Existing study on the relationship between market volatility and momentum are mostly conducted in developed countries. This study provides insight into the momentum strategies, market volatility, and business cycle variables in emerging markets like Pakistan. The same model may be tested in other emerging markets so that consistency of the result is ensured.

\section{References}

Avramov, D., Chordia, T., Jostova, G., \& Philipov, A. (2007). Momentum and credit rating. The journal of Finance, 62(5), 2503-2520.

Barroso, P., \& Santa-Clara, P. (2015). Momentum has its moments. Journal of Financial Economics, 116(1), 111-120.

Blitz, D., Huij, J., \& Martens, M. (2011). Residual momentum. Journal of Empirical Finance, 18(3), 506-521.

Sukkur IBA Journal of Management and Business | Volume 4 No. 1 January - June 2017 @ Sukkur IBA University 
Brunnermeier, M. K., Nagel, S., \& Pedersen, L. H. (2008). Carry trades and currency crashes. NBER macroeconomics annual, 23(1), 313-348.

Chordia, T., \& Shivakumar, L. (2002). Momentum, business cycle, and time-varying expected returns. The journal of Finance, 57(2), 985-1019.

Conrad, J., \& Kaul, G. (1998). An anatomy of trading strategies. The Review of Financial Studies, 11(3), 489-519.

Cooper, M. J., Gutierrez, R. C., \& Hameed, A. (2004). Market states and momentum. The journal of Finance, 59(3), 1345-1365.

Daniel, K., Hirshleifer, D., \& Subrahmanyam, A. (1998). Investor overconfidence, covariance risk, and predictors of securities returns. Journal of Finance, 53, 1839-1886.

Grundy, B. D., \& Martin, J. S. M. (2001). Understanding the nature of the risks and the source of the rewards to momentum investing. The Review of Financial Studies, 14(1), 29-78.

Hallerbach, W. G. (2012). A proof of the Optimality of Volatility Weighting over time.

Hallerbach, W. G. (2014). On the expected performance of market timing strategies. The Journal of Portfolio Management, 40(4), 42-51.

Harvey, C. R., \& Whaley, R. E. (1992). Market volatility prediction and the efficiency of the S \& P 100 index option market. Journal of Financial Economics, 31(1), 43-73.

Hodoshima, J., Garza-Gómez, X., \& Kunimura, M. (2000). Cross-sectional regression analysis of return and beta in Japan. Journal of Economics and Business, 52(6), 515-533.

Hong, H., Lim, T., \& Stein, J. C. (2000). Bad news travels slowly: Size, analyst coverage, and the profitability of momentum strategies. The journal of Finance, 55(1), 265-295.

Hong, H., \& Stein, J. C. (1999). A unified theory of underreaction, momentum trading, and overreaction in asset markets. The journal of Finance, 54(6), 2143-2184.

Hou, K., \& Moskowitz, T. J. (2005). Market frictions, price delay, and the cross-section of expected returns. The Review of Financial Studies, 18(3), 981-1020.

Jegadeesh, N., \& Titman, S. (1993). Returns to buying winners and selling losers: Implications for stock market efficiency. The journal of Finance, 48(1), 65-91.

Jegadeesh, N., \& Titman, S. (2001). Profitability of momentum strategies: An evaluation of alternative explanations. The journal of Finance, 56(2), 699-720.

Jegadeesh, N., \& Titman, S. (2002). Cross-sectional and time-series determinants of momentum returns. The Review of Financial Studies, 15(1), 143-157.

Jiang, G., Lee, C. M., \& Zhang, Y. (2005). Information uncertainty and expected returns. Review of Accounting Studies, 10(2), 185-221.

Lee, C., \& Swaminathan, B. (2000). Price momentum and trading volume. The journal of Finance, 55(5), 2017-2069.

Lo, A. W., \& MacKinlay, A. C. (1990). When are contrarian profits due to stock market overreaction? The Review of Financial Studies, 3(2), 175-205.

Sukkur IBA Journal of Management and Business | Volume 4 No. 1 January - June 2017 @ Sukkur IBA University 
Makarov, I., \& Rytchkov, O. (2012). Forecasting the forecasts of others: Implications for asset pricing. Journal of Economic Theory, 147(3), 941-966.

Moskowitz, T. J., \& Grinblatt, M. (1999). Do industries explain momentum? The journal of Finance, 54(4), 1249-1290.

Rouwenhorst, K. G. (1998). International momentum strategies. The journal of Finance, 53(1), 267-284.

Stivers, C., \& Sun, L. (2010). Cross-sectional return dispersion and time variation in value and momentum premiums. Journal of Financial and Quantitative Analysis, 45(4), 987-1014.

Wang, K. Q., \& Xu, J. (2015). Market volatility and momentum. Journal of Empirical Finance, 30, 79-91.

Zhang, B., \& Li, X. (2006). Do calendar effects still exist in the Chinese stock markets? Journal of Chinese Economic and Business Studies, 4(2), 151-163.

Sukkur IBA Journal of Management and Business | Volume 4 No. 1 January - June 2017 @ Sukkur IBA University 102 